\title{
HIGHLIGHTS
}

OBESITY

\section{Thyroid function alterations in individuals following weight loss by laparoscopic gastric banding}

The evidence is conflicting as to whether weight loss has subsequent effects on circulating thyroid hormone levels. Dall'Asta et al. now report altered levels of free $T_{3}$ and free $T_{4}$ in a large group of obese patients with normal thyroid function following weight loss achieved through laparoscopic gastric banding. "[Previous] studies were performed in small series of subjects and/or for short periods, techniques to obtain weight loss were extremely different, and control subjects were not included," write the authors.

Prior to surgery, levels of TSH, free $\mathrm{T}_{3}$ and free $\mathrm{T}_{4}$ were higher in 258 patients with obesity than in 99 healthy participants; however, all thyroid hormone levels were within the normal range. Following weight loss by laparoscopic gastric banding, the researchers noted a significant decrease in free $\mathrm{T}_{3}$ levels and a significant increase in free $\mathrm{T}_{4}$ levels (which led to an
4 thyroid hormone alterations

... may be caused by decreased

activity of D1 and D2

iodothyronine deiodinases 77

overall decrease in the free $\mathrm{T}_{3}$ :free $\mathrm{T}_{4}$ ratio) in individuals with obesity when compared to measurements in healthy controls. In contrast to previous studies, there was no comparative difference between TSH level changes in patients with obesity after weight loss and corresponding levels in healthy controls-the authors stress such discrepancies may be due to varying methods of weight loss and increased weight reduction in previous studies. Furthermore, the free $\mathrm{T}_{3}$ : free $\mathrm{T}_{4}$ ratio correlated with BMI in obese patients at 6 and 12 months following surgery, whereas free $\mathrm{T}_{3}$, free $\mathrm{T}_{4}$ and free $\mathrm{T}_{3}$ : free $\mathrm{T}_{4}$ ratio changes correlated with a decrease in body weight at 12 months following surgery.

The authors speculate that the thyroid hormone alterations following weight loss in patients with obesity may be caused by decreased activity of D1 and D2 iodothyronine deiodinases-enzymes that convert free $\mathrm{T}_{4}$ to free $\mathrm{T}_{3}$ - or to changes in $\mathrm{T}_{3}$ conversion rates. "The hypothalamicpituitary-thyroid axis could be altered as TSH is not responding to the decline in $\mathrm{T}_{3}$, perhaps due to site-specific changes in D2 activity [or] more specifically increased hypothalamic D2 activity during caloric restriction," write the authors.

Rowan Higgs

Original article Dall'Asta, C. et al. Weight loss through gastric banding: effects on TSH and thyroid hormones in obese subjects with normal thyroid function. Obesity doi:10.1038/oby.2009.320 